\title{
O DESIGN CONTEMPORÂNEO COMO DISCIPLINA INTEGRADORA DA CULTURA TECNOLÓGICA
}

\author{
Maria do Carmo Gonçalves Curtis \\ Universidade Federal do Rio Grande do Sul - UFRGS \\ maria.curtis@ufrgs.br \\ Liane Roldo \\ Universidade Federal do Rio Grande do Sul - UFRGS \\ liane.roldo@ufrgs.br
}

\section{Resumo}

Desde meados do século XX têm ocorrido mudanças significativas na sociedade contemporânea, e o design constitui um campo que evidencia o contexto cultural e tecnológico dessa situação. Neste trabalho são articulados o pensamento de R. Buchanam (1992) quando sugere que o design seja considerado como uma nova arte liberal, proposição reforçada por G. Swanson $(1994 ; 2004)$ no contexto específico da educação em design. Também apresenta-se conceituações de cultura tecnológica e de tecnologia, uma vez que constituem o pano de fundo da discussão. A intenção em desenvolver a proposta é conjeturar a respeito dos direcionamentos relativos à educação em design, tendo em vista as progressivas transformações culturais e tecnológicas vividas pela sociedade contemporânea, e assinalar que tão importante quanto o saber técnico é refletir a respeito das repercussões sociais da intervenção técnica.

Palavras-chave: Ensino em design, tecnologia, artes liberais.

\section{CONTEMPORARY DESIGN AS INCLUSIVE OF DISCIPLINE TECHNOLOGICAL CULTURE}

\section{Abstract}

This paper articulated the thought of R. Buchanan (1992) suggests that when the design is considered as a new liberal art, enhanced by G. Swanson (1994, 2004) proposition in the specific context of design education. Also presents conceptions of technological culture and technology, since they constitute the background of the discussion. The intention is to develop the proposed conjecture about new directions in design education that can follow, considering the progressive technological transformations experienced by contemporary society, in particular noted that as important as technical knowledge is a reflection about the social repercussions technical intervention.

Keywords: Teaching in design, technology, liberal arts. 


\section{INTRODUÇÃO}

Este artigo trata a respeito do ensino em design, partindo do pensamento de dois autores que propõem a possibilidade de conceber o design como uma nova arte liberal. De acordo com Buchanam (1992), a cultura tecnológica, característica do momento atual, seria a base para tal proposta. E de modo complementar, mas enfatizando o contexto específico educacional, Sawson (1994, 2004) aborda a questão numa perspectiva crítica restrita à formação profissional em design gráfico. Somados aos dois autores, buscou-se fundamentar a cultura tecnológica e tecnologia a partir de Maldonado (2006), em seus escritos relativos aos aspectos teóricos do campo e a Mario Bunge (1980), que trata da questão epistemológica na contemporaneidade. Ainda P. Lévy (1999) respalda o embasamento relativo às relações estabelecidas entre tecnologia, cultura e sociedade. O objetivo deste trabalho é realçar a dimensão integradora do design contemporâneo enquanto disciplina que, justamente por não possuir um objeto exclusivo de estudo, tem vocação para estabelecer conexões na multifacetada rede de conhecimentos da atualidade. Mais que o saber técnico, instrumental, o design contemporâneo reflete a relação humana no contexto de uma cultura que é chamada de tecnológica.

Para este artigo, enquanto referencial teórico, procurou-se estabelecer uma 'interlocução' entre os autores mencionados, a fim de encontrar os nexos conceituais que respaldam o objetivo principal do trabalho. Um aspecto marcante foi a constatação de que é possível obter articulações produtivas entre as diferentes perspectivas expressas, rumo a uma compreensão mais clara a respeito das implicações do ensino em design no contexto contemporâneo.

\section{DESIGN COMO ARTE LIBERAL: implicações na educação}

Conforme Buchanam (1992), a cultura está se transformando de modo revolucionário desde o século $X X$, e o design é uma das áreas em que esta mudança é evidente. $O$ autor destaca que a variedade de pesquisas publicadas em conferências, papers, artigos de jornal, livros, atesta que o design está se expandindo em seus significados e conexões práticas. Apesar de ser mais frequente conectar as artes e ciências tradicionais institucionalizadas no ensino superior, Buchanam (1992) admite que o design tem ampliado seu espectro de atuação neste processo desde uma atividade comercial para um campo profissional em estreita relação com a pesquisa técnica. Ele afirma que a variedade de pesquisas, somada à amplitude de atuação do design, constitui fator que justifica reconhecê-lo como uma nova arte liberal da cultura tecnológica corrente.

Por seu turno, Swanson (1994, 2004) defende o design como arte liberal, abordando a questão no contexto mais estrito do ensino, numa perspectiva bastante crítica quanto ao teor dos programas de ensino, orientados prioritariamente a uma formação profissionalizante. Para o autor, essa postura pode desencadear uma situação problemática aos futuros designers, uma vez que, do ponto de vista operacional, a atividade está estreitamente vinculada às transformações tecnológicas nas áreas da comunicação e informação. Em suma, a principal argumentação é que o ensino do design como arte liberal constitui uma alternativa em direção a uma concepção mais ampla de educação, pautada pelo equilíbrio entre competências técnicas (saber fazer) e compreensão em geral (o pensar sobre o fazer). 
A arguição dos autores pró arte liberal, apesar de partir de diferentes ângulos, converge na relação que ambos sublinham no tocante às implicações existentes entre tecnologia, cultura e sociedade. Tais implicações constituem o pano de fundo deste debate, seja no ensino em design, seja no design enquanto atividade profissional. De nossa parte, buscou-se expor o tema articulando os autores, delineando a questão principalmente no contexto do ensino em design, devido à nossa atuação na dupla condição: docente na graduação e discente no contexto da pós-graduação.

\subsection{Evolução das Artes Liberais no Ocidente: de um livre pensar até a educação cultivada}

A visão clássica das artes liberais floresce na Antiguidade, quando o conceito foi esquematizado pela primeira vez por Aristóteles. Ele caracterizou os estudos liberais como a educação de um homem livre, mas sua definição implicava outros aspectos:

(1) as artes liberais não são mecânicas; (2) nem utilitárias, ou seja, têm um valor intrínseco; (3) as áreas de estudos liberais não são especializadas (isso restringiria a mente); (4) o estudo das artes liberais visa estritamente seu valor intrínseco. Swanson (1994) sublinha que apesar do interesse principal no valor intrínseco das arte liberais, Aristóteles reconheceu a sua utilidade na construção de uma sociedade democrática: o desenvolvimento da razão, da base moral e a busca da verdade eram os pré-requisitos para a cidadania em seu sentido mais pleno na Grécia clássica.

Nesta breve contextualização, importa frisar que a distinção de estudos liberais e mecânicos se originou numa sociedade em que o trabalho de rotina foi delegado à mão de obra escrava. Assim, há uma clara distinção (e consequente discriminação) entre o trabalho manual e o trabalho intelectual na origem histórica das artes liberais. Ao especificar melhor o teor das artes liberais, cabe mencionar que a Antiguidade clássica greco-romana constituiu as sete artes liberais: as artes da palavra - o trivium (gramática, lógica, e a retórica); e os estudos dos números - o quadrivium (aritmética, geometria, música e astronomia). No período medieval, a razão foi subordinada à revelação divina até que São Tomás de Aquino (1225-1274) conciliou a doutrina cristã e a filosofia aristotélica com a adição da teologia, ou seja, é a razão que induz ao conhecimento revelado por Deus. O marco seguinte deste percurso epistemológico foi o humanismo da Renascença, que redescobriu a educação liberal aristotélica através da literatura clássica e igualou a educação liberal com os estudos literários (SWANSON, 1994).

A continuidade deste processo culmina no século XIX, cuja visão passa a ser de uma educação enciclopédica que incluía Belas Artes, belleslettres, história, ciências naturais e matemática, filosofia e as incipientes ciências sociais. Enfim, trata-se da educação cultivada que abarcava todas as disciplinas mencionadas anteriormente. Este amplo círculo de aprendizado foi dividido em determinados assuntos, cada um com um método adequado ou conjunto de métodos adequados para a sua exploração. No seu auge como artes liberais, esses assuntos permitiam uma compreensão integrada da experiência humana e da matriz de conhecimento disponível (BUCHANAM 1992). Mas tal compreensão integrada da experiência humana, no complexo contexto contemporâneo, está se tornando cada vez mais inviável, devido à celeridade dos avanços da cultura tecnológica. 


\subsection{Cultura Tecnológica: relações entre tecnologia, cultura e sociedade}

“Do ponto de vista antropológico, o design é uma entre diversas atividades projetuais, tais quais as artes, o artesanato, a arquitetura, a engenharia, e outras que visam a objetivação no seu sentido estrito, ou seja dar existência concreta e autônoma a ideias abstratas e subjetivas." Rafael Cardoso, 1998

A tecnologia condiciona a cultura, não a determina. Nesse sentido, condicionar significa oferecer possibilidades que podem ser aproveitadas ou não (LEVY, 1999). A tecnologia conforma a mentalidade, a linguagem, a maneira de estruturar o pensamento e aponta quais os valores são prioritários. Constitui o conjunto referencial no qual os demais fenômenos sociais podem ser encaixados. A cultura, por sua vez, tem seus valores já arraigados, os quais são questionados na medida em que a sociedade evolui tecnologicamente. Assim, ainda que a tecnologia em si não tenha autonomia sobre a sociedade, há muitas implicações na relação entre sociedade, cultura e tecnologia. Existem relações de reciprocidade, de interação, por isso não se deve tratar a tecnologia como determinante das mudanças sociais. A tecnologia é um dos campos adaptativos da cultura, a partir do qual outras mudanças adaptativas e culturais se realizam. Como exemplo de mudanças adaptativas, pode-se mencionar a comunicação, a informação e as alterações nos conceitos de tempo e espaço ${ }^{1}$.

A tecnologia não se constitui como um fenômeno isolado, precisa ser compreendida a partir das relações que estabelece. "A tecnologia moderna cresce na mesma terra que ela fertiliza: a civilização industrial e a cultura moderna." Ela está fundamentada no conhecimento trivial e algumas habilidades artesanais, no conhecimento científico e no conhecimento matemático. Portanto, a tecnologia se articula a outros modo de conhecer (BUNGE, 1988).

O teórico Tomas Maldonado² (2006, p.18), ao conceituar design industrial, destaca os "numerosos entrelaçamentos e pontos de contato imbricados na sua base conceitual". Segundo o autor, para captar sua importância é preciso tomar ciência da abrangência das implicações do design industrial. Como toda atividade projetiva que intervém na relação produção-consumo, o design industrial é uma força produtiva que contribui para a organização e socialização das outras forças produtivas com que interage. O designer, continua Maldonado, faz a mediação entre necessidades e objetos, entre produção e consumo. Entretanto, imerso no cotidiano de sua atividade, dificilmente consegue detectar a incidência social de sua profissão, a qual costuma ser traduzida por uma intervenção isolada, sendo percebida (e auto percebida) principalmente como "um serviço prestado à indústria" (ou cliente).

Em todas as sociedades existe um ponto crítico, em que o processo de produção e reprodução material acontece. E situado neste ponto crítico, o design industrial emerge enquanto "fenômeno social total", o que significa que precisa ser analisado em relação com outros fenômenos, junto aos quais forma "um único tecido conectivo". Maldonado (2006) identifica a técnica como pertencente a mesma

\footnotetext{
${ }^{1}$ Para aprofundar o tema das alterações nas relações de tempo e espaço ver livro de Stuart Hall, A identidade cultural na Pós-modernidade, Rio de Janeiro: DP\&A, 2006, pp.67-77.

2 É importante mencionar que a data de 2006 indicada na citação é da edição que foi consultada, porque o texto de Tomás Maldonado que fundamenta a argumentação foi editado, originalmente, em 1991.
} 
categoria, salientando que "a técnica está presente, quer na execução dos 'produtos estruturais' (configurações objetivas de todos os tipos), quer na dos 'produtos supra estruturais' (configurações simbólicas de todos os tipos)". Um argumento que interessa especialmente no âmbito deste trabalho é que a oposição dos produtos estruturais aos supra estruturais, ou seja, a oposição dos produtos da mão (e da máquina) aos da cabeça foi superada desde que os produtos do trabalho humano são considerados como artefatos (MALDONADO, 2006). Este é o pressuposto que fundamenta o conceito contemporâneo de cultura material ${ }^{3}$.

Após essas considerações acerca o design industrial, cita-se P. Lévy (1999), que indica os dispositivos comunicacionais e informacionais como os maiores produtores de mudanças culturais, pois definem a relação entre os seres humanos e os meios de comunicação e informação. Desse modo, o autor conclui que a tecnologia é uma peça importante na formação cultural da sociedade. Assim como toda realidade cultural, o mundo tecnológico possui sua própria lógica interna. O sujeito precisa ter competências para relacionar a multiplicidade de procedimentos culturais com os contextos em que são produzidos, para que as suas práticas e concepções façam sentido, a fim de articular-se nestes contextos. Lévy (1999) destaca que, por exemplo, para integrar-se a uma comunidade virtual, é necessário conhecer seus membros e também que eles o reconheçam como um par, e isto equivale a um processo de socialização e aculturação. Tal equivalência valida a importância do universo cultural relacionado às questões tecnológicas na sociedade contemporânea.

A familiaridade entre o ser humano e objeto técnico, decorrente da onipresença da tecnologia no mundo atual, transforma as relações socais. Ao longo do processo evolutivo, a cultura conduz as relações do homem na sociedade e, especificamente na atualidade, se o sujeito possui as competências técnicas, a cultura tecnológica facilita o seu processo de socialização. Entretanto, a presente reflexão sobre cultura tecnológica pretende frisar que a compreensão das evoluções tecnológicas, ocorridas na sociedade atual, não são restritas à operacionalidade de novos equipamentos e produtos, ou seja, não se esgotam em competências técnicas. A repercussão social da cultura tecnológica é de ordem mais abrangente, incidindo nas condutas, conferindo mudanças à cultura existente e modificando indivíduos, grupos e sociedade. Portanto, interfere "na execução dos 'produtos estruturais' (configurações objetivas de todos os tipos) e na execução dos 'produtos supra estruturais' (configurações simbólicas de todos os tipos)", parafraseando Maldonado (2006).

Após essas considerações, fica evidente que a cultura, design e a tecnologia, possuem uma natureza abrangente e relações de reciprocidade e interação. Salientase então, um caráter de integração a ser abordado neste trabalho.

\footnotetext{
${ }^{3}$ Para maiores informações a respeito de 'cultura material', ver artigo de Rafael Cardoso, Design, Cultura Material e Fetichismo dos Objetos, in: Revista Arcos, Volume 1, Número Único, 1998.
} 


\subsection{Compartimentalização do saber, uma formação fragmentada}

Retomando o ponto relativo à educação, até o final do século XIX, os indivíduos se deparavam com métodos cada vez mais refinados e novos assuntos foram adicionados conforme os avanços no conhecimento. Como resultado, o círculo de aprendizagem foi dividido e subdividido, constituindo um progressivo e extenso conjunto de especializações. Atualmente, estudos especializados florescem, gerando um leque cada vez mais rico e detalhado de fatos e valores. Mas a consequência da progressiva especialização é contraditória. Por um lado, permite avanços no conhecimento e, por outro lado, instaura uma problemática fragmentação no contexto educacional. O resultado é uma infinidade de assuntos, com escopos cada vez mais estreitos, estanques entre si, sem conexões diretas com a vida diária das pessoas (BUCHANAM, 1992).

Conforme Swanson (1994), em grande parte os padrões de excelência e os caminhos do progresso na carreira nas universidades são mais evidentes na pesquisa, nas publicações especializadas do que no ensino orientado à iluminação pessoal, uma educação ampla. As artes liberais têm se tornado uma mera lista de campos de definição em vez de uma abordagem integrada para a aprendizagem. Mesmo que a grande maioria dos estudantes não tenha a intenção de especializar-se em um determinado assunto acadêmico, as aulas tendem a ser preparatórias para uma futura pós-graduação. Ao criticar a ênfase na profissionalização do ensino, Swanson (1994) adverte que os futuros postos de trabalho tendem a se diferenciar da atualidade. Portanto, um ensino pautado pela formação de operadores de computador, está fadado a tornar-se obsoleto em pouco tempo:

“Educadores podem e devem examinar as tendências (sabemos, por exemplo, que a comunicação eletrônica vai proliferar e ficar mais flexível do que é atualmente) e tentar preparar a si mesmos e seus alunos para o futuro. Porém, há apenas uma coisa que nós realmente sabemos com precisão sobre o futuro: será diferente de hoje. Portanto, o melhor que podemos fazer pelos estudantes de design é torná-los adaptáveis." (SWANSON, 1994, p.60) $)^{4}$

Mencionando a mudança de nomes dos 'programas de arte comerciais' para 'publicidade', do 'projeto de design gráfico' para 'comunicação visual', Sawson indica que isso testemunha o fato de que no futuro os designers gráficos provavelmente estarão atuando de modo diferente no mercado. Assim, cabe a seguinte questão: é viável conceber programa de ensino de design que contemple esse cenário futuro de mudanças? Como tornar os programas mais adequados à adaptabilidade dos estudantes sublinhada por Swanson? A dimensão integradora do design pode ser um caminho.

\footnotetext{
${ }^{4}$ Tradução livre. No original:

Educators can and should examine trends (we know, for instance, that electronic communication will increase and become more flexible than it is currently) and try to preparethemselves and their students for the future. There is only one thing, however, that we really know with precision about the future-it will be different from today. Therefore, the best thing we can do for design students is to make them adaptable.
} 


\subsection{Design enquanto disciplina integradora}

"Designers, educadores de design e estudantes de design pertencem a um campo mais importante e interessante do que parecem reconhecer." Gunnar Swason, 1994

Frente ao quadro de compartimentalização do saber, a busca por novas disciplinas integradoras, para complementar as artes e as ciências, tornou-se um dos temas centrais da vida intelectual e prática no século XX (BUCHANAM, 1992). Na contemporaneidade, o contexto cultural fragmentário amplia a pertinência dos estudos liberais, ao evidenciar a necessidade de redimensionar a educação numa perspectiva mais convergente e conectada (SWANSON, 1994, BUCHANAM, 1992). O que implica conceber o design como uma arte liberal? A chave para o design "liberal" exige uma mudança de perspectiva no ensino. Começa por adquirir a confiança na própria retórica e por compreender o design como um campo que faz a conexão de muitos assuntos que tratam da comunicação, expressão, interação, cognição, educação, engenharia, materiais. De acordo com Swanson (1994), há muitas ligações disciplinares nas quais o design gráfico pode ser uma ponte: a ciência e a literatura, a sociologia e a história, a antropologia e a ciência política, a arte e a educação.

Qual a direção que o design precisa tomar como um campo liberal? É difícil responder a tal indagação, mas é possível partir de uma constatação peculiar ao campo. Diferente da maioria dos campos tradicionais de estudos, o design não tem nenhum objeto próprio, por isso é complicado encontrar modelos pré-concebidos para este novo enfoque. Cabe à comunidade envolvida no contexto específico do ensino debater acerca desta direção. Nesse viés, a ausência de um objeto de estudo implica outra face da questão: é que a natureza abrangente da atividade do design implica o projetar em resposta a uma situação dada, isto é, solucionar um problema que lhe é externo. Este quadro explica porque a grande maioria dos programas de graduação em design inclui prioritariamente competências técnicas. Em contrapartida, Swanson (1994) ressalta que nos programas de outros campos de estudo, por exemplo, línguas, química ou ciências sociais, há maior diversidade nas abordagens pedagógicas. $\mathrm{O}$ autor admite que o saber técnico constitui uma grande parte de qualquer programa de design, mas adverte que no futuro o significado das técnicas vai assumir maior importância. Quais os programas que serão mais adequados à adaptabilidade dos estudantes? Nessa linha de pensamento, ele argumenta ser favorável a um maior equilíbrio entre competências e compreensão. "A principal tarefa da educação em design é encontrar o equilíbrio entre o treinamento de competências e uma compreensão geral que irá beneficiar os alunos, no campo do design gráfico, e os profissionais gráficos" (SAWSON, 1994, p.62). Cabe especificar que compreensão refere-se à capacidade de refletir sobre sua ação no mundo, e diz respeito à cidadania, em última análise, a uma formação humanista que complementa a profissionalizante.

Num trabalho posterior sobre o mesmo tema, Swanson (2004) aponta para aspectos específicos do campo, os quais podem servir de elementos balizadores para conceber o design como uma arte liberal: a expertise em complexidade e o pensamento sistêmico. $\mathrm{O}$ autor destaca que devido à ausência de objeto próprio constituir a natureza de sua atividade prática, os designers desenvolvem padrões de trabalho interativos adequados para enfrentar a incerteza, o que Ihes permite lidar com a complexidade com mais fluência do que profissionais de outros campos 
costumam ter. E, dado o caráter abrangente e conectivo, o pensamento sistêmico é marca de uma perspectiva específica de design. Ele afirma que outras áreas da academia poderiam se beneficiar desta compreensão multidisciplinar. Hoje, pode-se acrescentar que a compreensão que caracteriza a prática do design é interdisciplinar.

\section{CONCLUSÃO}

" Assim, a Bauhaus foi inaugurada em 1919 com o específico objetivo de realizar uma moderna 'arquitetura arquitetônica', que, como a natureza humana, era para ser abrangente em seu escopo (...). O nosso princípio orientador foi que projeto não é uma questão material nem intelectual, mas simplesmente uma parte integrante das coisas da vida, necessária para todos em uma sociedade civilizada. " Walter Gropius, 1937

Desde a oposição conceitual entre arte liberais e artes mecânicas, os produtos e os profissionais da técnica foram discriminados durante séculos. A origem desta discriminação, como já foi assinalada, remonta à sociedade escravagista grega, com seu desprezo pelo trabalho manual e mecânico. Para Maldonado (2006), a superação de tal discriminação resulta das etapas históricas que possibilitaram o advento do design industrial. Processo que ocorre ao longo do século XX, no debate sobre como a relação arte-técnica influenciou a evolução da arquitetura moderna e como esta evolução condicionou aquele debate. Assim, na história do design moderno, é possível encontrar uma elucidação a respeito de como o design industrial, ao ser considerado como mediador entre a arte e a técnica, superou, parcialmente, o antigo preconceito ideológico contra a técnica.

A alusão à história do design moderno na epígrafe assinala que a discussão sobre a dimensão integradora do design não é recente, mas remonta às origens do modelo de formação em design: a Bauhaus. Na contemporaneidade, esta dimensão integradora, tão necessária, é menos aparente devido, entre outros motivos, às céleres transformações operacionais que a cultura tecnológica imprime na vida cotidiana, assim como à crescente compartimentalização do saber. Entretanto, características inerentes à prática projetual do design podem funcionar como atributos valiosos em resposta a esse quadro problemático, de transformações cada vez mais rápidas na operacionalidade da tecnologia e o acúmulo de conhecimento. Os atributos citados formam o contexto no qual os designers lidam com esta complexidade e o seu pensar sistêmico.

Por outro lado, via de regra, o designer é absorvido de tal modo nos aspectos técnico-funcionais de sua atividade que dificilmente consegue detectar a repercussão social de sua profissão, a qual costuma ser traduzida socialmente (e auto percebida) como uma intervenção isolada. Restringindo assim o valor dos atributos relativos à complexidade e ao pensar sistêmico ao escopo específico de cada projeto, sem estabelecer articulações que possam integrá-lo com a sociedade como um todo.

Nesse sentido, conceber o ensino do design numa abordagem de nova arte liberal pode nos aproximar de modelos de educação que se pautam por uma postura mais humanista que a racionalidade instrumental típica de nossa época. Relativizadas, as diferenças contextuais da Antiguidade clássica escravagista ou do elitismo da era vitoriana, as artes liberais nos aproximam da excelência da proposta de Aristóteles que reconheceu a utilidade das artes liberais na construção de uma sociedade democrática, porque esse enfoque estimula o desenvolvimento da razão, pautada por uma base moral, pré-requisitos para a cidadania clássica, os quais permanecem válidos na 
contemporaneidade. Enquanto educação cultivada, isenta do etnocentrismo da era vitoriana, as artes liberais possibilitam uma educação permeada pela compreensão mais integrada da experiência humana e do conhecimento disponível. Em geral, a amplitude (estreita) do projeto de escolaridade não tem ajudado os alunos a se tornarem pessoas que possam contribuir a moldar uma sociedade democrática, embora as ferramentas de análise e visão de muitas disciplinas tenham ampla aplicação extra disciplinar para compreender o mundo.

Se a tecnologia é um dos campos adaptativos da cultura, a partir do qual outras mudanças adaptativas e culturais se realizam, a relação que o homem estabelece com a tecnologia abrange um processo de apropriação da cultura tecnológica que influencia diretamente a sua atuação na sociedade em rede. A cultura tecnológica, pano de fundo no qual o design se insere, pode ser compreendida como um conjunto complexo de valores, comportamentos, linguagens, hábitos e relações sociais próprios da sociedade tecnológica contemporânea, esboçada a partir das inovações nos meios de comunicação e informação, entre outros. A vantagem do ensino em design como arte liberal está em conciliar o saber técnico com uma formação mais humanista, que habilite o estudante a agir na sociedade do futuro (nem tão distante), por meio da atividade projetual potencializada pela dimensão integradora do qual se apropria e constrói a sua identidade, tornando-se um cidadão mais consciente das repercussões sociais do exercício da sua profissão.

Uma possibilidade para trabalhos futuros reside na concepção de um projeto pedagógico que tenha por premissa a ideia central expressa nesta conclusão: conciliar o saber técnico com uma formação mais humanista, que forme o designer capacitado a atuar na sociedade do futuro (reitera-se nem tão distante), por meio da atividade projetual potencializada pela dimensão integradora do design.

\section{REFERÊNCIAS}

BUCHANAM, Richard. Wicked Problems in Design Thinking, Design Issues, Vol. 8, No. 2

(Spring, 1992), pp. 5-21, The MIT Press.

BUNGE, Mario. Epistemologia: curso de atualização. São Paulo: Editora da Universidade de São Paulo, 1980.

GROPIUS, Walter. The scope of the overall architecture. New York: Collier Books, 1970.

LÉVY, Pierre. Cibercultura. São Paulo: Editora 34,1999.

MALDONADO, Tomás. Design Industrial. Lisboa: Edições 70, 2006.

SWASOM, Gunnar. Graphic Design Education as a Liberal Art: Design and Knowledgein the University and the "Real World" Design Issues Volume X №1, (Spring, 1994), pp. 53-64, the MIT Press.

SWASOM, Gunnar. Liberal Arts and Graphic Design: Six Cautionary Questions, s/l, s/e, 2004. 